\title{
Engaging in patient decision-making in multidisciplinary care for amyotrophic lateral sclerosis: the views of health professionals
}

This article was published in the following Dove Press journal:

Patient Preference and Adherence

26 September 2012

Number of times this article has been viewed

\author{
Anne Hogden' \\ David Greenfield' \\ Peter Nugus' \\ Matthew C Kiernan ${ }^{2}$ \\ 'Centre for Clinical Governance \\ Research, Australian Institute of \\ Health Innovation, University of New \\ South Wales, ${ }^{2}$ Prince of Wales Clinical \\ School, University of New South \\ Wales, and Neuroscience Research \\ Australia, Sydney, New South Wales, \\ Australia
}

Background: The aim of this study was to explore clinician perspectives on patient decisionmaking in multidisciplinary care for amyotrophic lateral sclerosis (ALS), in an attempt to identify factors influencing decision-making.

Methods: Thirty-two health professionals from two specialized multidisciplinary ALS clinics participated in individual and group interviews. Participants came from allied health, medical, and nursing backgrounds. Interviews were audio recorded, and the transcripts were analyzed thematically.

Results: Respondents identified barriers and facilitators to optimal timing and quality of decision-making. Barriers related to the patient and the health system. Patient barriers included difficulties accepting the diagnosis, information sources, and the patient-carer relationship. System barriers were timing of diagnosis and symptom management services, access to ALSspecific resources, and interprofessional communication. Facilitators were teamwork approaches, supported by effective communication and evidence-based information.

Conclusion: Patient-centered and collaborative decision-making is influenced by a range of factors that inhibit the delivery of optimal care. Decision-making relies on a fine balance between timing of information and service provision, and the readiness of patients to receive them. Health system restrictions impacted on optimal timing, and patients coming to terms with their condition. Clinicians valued proactive decision-making to prepare patients and families for inevitable change. The findings indicate disparity between patient choices and clinician perceptions of evidence, knowledge, and experience. To improve multidisciplinary ALS practice, and ultimately patient care, further work is required to bridge this gap in perspectives.

Keywords: patient decision-making, multidisciplinary care, amyotrophic lateral sclerosis, barriers and facilitators, health professional perceptions

\section{Introduction}

Amyotrophic lateral sclerosis (ALS) is a progressive and terminal multisystem disorder. ${ }^{1,2}$ The worldwide incidence of the disease is estimated at 2.65 per 100,000 people. As yet, a cure is unavailable, and treatment is focused on symptom management ${ }^{3}$ and enhancement of patient quality of life. ${ }^{4}$ Death frequently results from respiratory failure, ${ }^{5}$ on average $2-5$ years after diagnosis. ${ }^{6}$ Symptom management in ALS involves a network of health professionals assisting patients to manage diverse changes in physical, cognitive, and behavioral function. ${ }^{7-9}$ Specialized multidisciplinary ALS clinics deliver integrated services from neurology, rehabilitation, and palliative care settings, linked with ALS associations. ${ }^{3,8,10}$ Care is underpinned by recurrent decisions about symptom management and quality of life as the patient's condition deteriorates. ${ }^{11}$ 
Patients' decisions may include uptake of artificial nutrition and hydration, ${ }^{12}$ assisted ventilation, ${ }^{13,14}$ equipment needs, ${ }^{15,16}$ advance care plans,${ }^{17}$ palliative care, ${ }^{18}$ and endof-life choices. ${ }^{19,20}$

Patient-centered decision-making is fundamental to multidisciplinary ALS care. ${ }^{21,22}$ It is delivered collaboratively between the patient, family, and health professionals, in reflection of high levels of carer involvement. ${ }^{23-26}$ Clinicians contribute to the decision-making process by providing patients and families with information, guidance, and support. ${ }^{27,28}$ Previous studies of decision-making in ALS care have focused on patient choices ${ }^{29,30}$ and the complexities surrounding these preferences, including the timing of discussions, ${ }^{31}$ decisionmaking capacity, ${ }^{32}$ the ethical issues of euthanasia, ${ }^{33}$ and treatment withdrawal. ${ }^{34}$ A review of shared decision-making in palliative care also identified patients' unmet information needs, unrealistic expectations, and tendencies to delay decisions as barriers to collaborative decision-making. ${ }^{35}$

Few studies have examined patient-centered care in specialized multidisciplinary ALS clinic settings, ${ }^{36}$ and we know very little of health professional experiences within multidisciplinary ALS care. A small number of studies of clinician perspectives have revealed the ethical, emotional, and professional difficulties encountered in managing patient deterioration. ${ }^{34,37-41}$ However, clinician views on patient decision-making processes for symptom management have not been sought. The inevitable patient decline places ALS symptom management at the intersection of system-level and personal complexities. Additionally, the progressive and heterogeneous character of $\mathrm{ALS}^{42}$ creates challenges for patient-centered decision-making under stressful and dynamic circumstances. Patient-centered decision-making for this multisystem disorder requires active integration of professional roles and perspectives. Health professional perceptions and experiences become important sources to drive improvements in ALS care. Gaining insight into practitioner views on decision-making is to reveal the challenges to patient-centered care and assist practice improvements, including informing the development of clinical guidelines and pathways. Therefore, the aim of this study was to explore patient decision-making for symptom management from the experience of health professionals, to identify factors influencing decision-making in specialized multidisciplinary ALS care.

\section{Participants and methods Participants and setting}

Convenience sampling was used to recruit participants into the study. ${ }^{43}$ Thirty-seven health professionals associated with two specialized multidisciplinary ALS clinics and regional advisors from the Motor Neuron Disease Association were invited to participate. The two clinics offered similar models of service provision. That is, patients living within the local health service area were assessed and managed by the clinical team, while those living outside the service area were seen for assessment and follow-up consultation. Symptom management for "out of zone" patients was provided by health services in the patients' local area. Both clinics had links to neurology, respiratory, gastroenterology, and palliative care services.

\section{Participant demographics}

Thirty-two participants ( $89 \%$ response rate) were recruited from medical, nursing, and allied health professions (Table 1). They worked primarily in acute inpatient, community-based rehabilitation, or palliative care services and attended the monthly ALS clinics in addition to their usual clinical load. A broad range of clinical experience was represented across diagnostic, rehabilitation, and palliative care phases. Participants had worked between one and 30 years in ALS care, and 59\% had more than 5 years of experience. Sixtynine percent of the health professionals were female.

\section{Data collection and analysis}

A structured interview guide (Table 2) was developed through a three-stage process. First, issues were identified from key articles within the decision-making literature. ${ }^{44-48}$ Then, to ensure relevance to multidisciplinary ALS care, questions were refined in reference to ALS decisionmaking. ${ }^{4,11,18,23,29,32,49}$ Finally, the topics were revised and verified in review with two expert clinicians from the clinic sites. These clinicians were selected because of their extensive clinical and research experience in ALS, and subsequently participated in the study. Twelve open-ended interview questions were derived. They explored the participants'

Table I Professional characteristics of participants

\begin{tabular}{ll}
\hline Profession/role & Number \\
\hline $\begin{array}{l}\text { Allied health (social work, physiotherapy, } \\
\text { occupational therapy, speech pathology, nutrition) }\end{array}$ & 13 \\
$\begin{array}{l}\text { Medicine (neurology, physical and rehabilitation } \\
\text { medicine, palliative medicine) }\end{array}$ & 9 \\
Nursing & 5 \\
Motor Neuron Disease Association regional advisor & 2 \\
Clinical researcher & 1 \\
Clinic coordinator & 1 \\
Palliative care volunteer & 1 \\
Total & 32 \\
\hline
\end{tabular}


Table 2 Interview guide

\begin{tabular}{ll}
\hline Theme & Question \\
\hline $\begin{array}{l}\text { Participant experience } \\
\text { with decision-making }\end{array}$ & A. Tell me about your experience in helping \\
& B. Whatients make decisions about their care. \\
& decision-making? \\
& C. What role do carers play \\
in decision-making? & D. What decisions do people with \\
& ALS need to make? \\
E. What do you see as the treatment \\
options available to patients? \\
FI. When has decision-making worked well? \\
F2. What has enabled it to work well? \\
Grocesses in \\
Gultidisciplinary care
\end{tabular}

Abbreviation: ALS, amyotrophic lateral sclerosis.

experience with patient decision-making, barriers to effective decision-making, and improvements for decision-making processes in multidisciplinary clinic care.

Data collection was conducted between April 2011 and February 2012. Written consent was obtained from each participant prior to interview. Human research ethics approvals were provided by the University of New South Wales and participating health services. Twenty-one indepth interviews were conducted with individual participants, and two group interviews were held with a palliative care nursing team and members of a multidisciplinary ALS clinic team. Three health professionals from the multidisciplinary group interview subsequently participated in individual interviews to provide their experience in more detail. All interviews took place in the participants' work environment, and lasted approximately 60 minutes. Audio recordings of the interviews were transcribed, and the transcripts were imported into QSR NVIVO 9 software (QSR International Pty Ltd, Melbourne, Australia) for management. The data were analyzed using stepwise thematic analysis. ${ }^{50,51}$ Participant interview statements were assigned codes of meaning, clustered into subthemes, and then condensed into overarching themes. Excerpts identifying barriers and facilitators to decisionmaking were selected for inclusion. Data were pooled across the two sites due to the small number of sites and participants.
Identities were protected by the removal of names and profession. Exemplar quotes are presented using participant numbers only.

\section{Results Influences on decision-making}

Clinicians reported that their aim was to guide the patient and carer through upcoming decisions. They sought to do this in a timely manner, by providing the patient and family with evidence-based information on the available options, in regular discussion of patients' projected health care needs. Practitioners saw their involvement as a cyclical process, responding to recurrent change as the condition of the patient deteriorated. They defined the objective of collaborative decision-making as facilitating patient-centered decisions to suit the inevitable changes to patient health and lifestyle.

Thematic analysis revealed two categories of factors impacting on patient decision-making, ie, patient and health system factors. Facilitators that promoted effective decisionmaking also emerged. These were teamwork, supported by strong interprofessional communication and evidence-based information.

\section{Patient factors}

Participants identified decision-making barriers they perceived to be presented by the patient. The three most significant were patient acceptance of the diagnosis, the types of information patients sourced, and the patient-carer relationship (Table 3). The clinicians experienced poor family dynamics, and problems with acceptance and insight as impacting on their relationship with the patient. Health professionals reported little control over these issues, but aimed to respond to the changing needs of their patients as best they could.

\section{Ability to accept the diagnosis}

Eighty-four percent of participants raised concerns with patients who experienced difficulties in coming to terms with the diagnosis of ALS, and adjusting to deterioration as the disease progressed.

Respondents identified limited clinical understanding of ALS as an impediment to acceptance of the diagnosis by both patients and their families. Two issues were listed as contributors to this perceived lack of insight. First, limited public awareness of ALS as a disease entity was seen to create delays in patients seeking a diagnosis. In addition, the shock patients experienced on receiving a terminal prognosis for an unfamiliar condition was reported to delay the patient's 
Table 3 Patient factors

\section{Ability to accept the diagnosis}

I. "It seemed to be more often the case in my perception that people were very reluctant to make big decisions, not quite believing that this was the case, or not quite believing that things were going to progress ... It feels like a mixture of hope and disbelief, with disbelief, I think, overwhelming the hope." (HPI5)

2. "It is very challenging when they don't accept the diagnosis, because if they don't do that, they don't accept any interventions. And there comes a point where it's too late to institute various interventions, which internally may then lead to sort of quite a severe, quite a nasty death on the part of the patients." (HP29)

3. "I don't think we actually pinpoint that very clearly ... and because they don't come across as a dementia patient, fair enough, but they're not performing normally. So they do have some sort of cognitive impairment which is not enough to be dementia, but they're not functioning as they used to. And l'm sure that is impacting in some way." (HP28)

4. "It could be like a lack of initiative to take the decisions. They [patients with cognitive and behavioral changes] will leave for later when usually people say, 'Look, no, we're deciding now'. And then sometimes people say 'We'll discuss this later', and later is too late. Important things like palliative care or who is going to take care of them." (HP30)

5. "You try and talk to them about that and they're not ready to hear it. They're not ready to, they don't want to talk about the long term accommodation option, and then it's literally a snap decision when they can't do it anymore. And so all of that pre-planning that you'd like to do is much more difficult, but you don't want to force them. So we'll scramble them all ... but it's not an ideal situation for their care." (HP4)

6. "It's about trying to be responsive to them when they are ready to hear, which is the same with any crisis situation. Because it is a crisis, and it feels like a series of crises. Crisis theory is 'respond at the time, do what you can, calm it down, normalize it, be ready for the next crisis'. And that's consistently how it feels." (HPI5)

\section{Types of information patients sourced}

7. “The Internet is so varied, that, we have patients regularly sending in information going, 'Oh, I've found this amazing machine that's going to solve all my problems'. And having to tell them, 'I realize you've found this and all the things sound really good, like online there's all these wonderful reviews about this system, but it doesn't work'.” (HP23)

8. "They often don't have realistic expectations of how much help the medical profession can provide. They're wanting cure, but at the same time not necessarily seeing what they're going to be kept alive to be." (HP20)

\section{Patient-carer relationship}

9. "I don't think you can only talk to the person with the ALS and find out just what they want, because what their carer wants might be totally different ... The client might say 'I want to stay home, it's the only thing I want to do', and the partner might be going 'There's no way I can handle, physically, their behaviors'. So you've got to take both into consideration." (HP7)

10. "There's so much family friction at times. You know where one is guarding the other, and I can think of one particular family where there was quite a number of family players involved, and they all seem to be hyper-protective, and not necessarily making the right decisions, or leaving, sort of leaving the person with ALS to make the decisions, but at the same time being gate-keepers. And you just know you could help this person more, but you can't get there." (HP2I)

Abbreviation: ALS, amyotrophic lateral sclerosis; HP, health professional.

and the family's ability to take in information, and to plan for future care needs (quote 1). Discussions for planning and decision-making were delayed by patients who were seen to use denial as a coping strategy (quote 2).

Second, $75 \%$ of respondents reported that cognitive and behavioral changes impacted on patients' health care decision-making. Clinicians distinguished between the mild changes frequently detected in ALS and the overt frontotemporal dementia that resulted in loss of decisionmaking capacity. However, the effects of subtle cognitive and behavioral change on decision-making were not easily specified (quote 3 ). Participants stated that patients frequently retained the capacity to make decisions. Nevertheless, the quality and timing of their decisions appeared compromised by a lack of motivation, and limited insight into their condition and the needs of their families (quote 4). Many patients were described as being "difficult" and having rigid personalities, particularly by clinicians working in the palliative phase of care. Because cognitive and behavioral change was not routinely assessed in the clinics, identification of patients at risk of impaired decision-making skills was neither systematic nor standardized. Health professionals explained that more specific and detailed knowledge of these changes could improve their approach with the patient and carer.

Participants reported that patients who struggled to accept their condition responded passively to physical deterioration, seeking assistance only when their condition had become unmanageable. They cited decisions made at the last moment, or, more catastrophically, after critical timing windows were lost (quote 5). The use of crisis management strategies was seen as the last resort for patients who were unable to come to terms with the changes to their life (quote 6).

\section{Types of information patients sourced}

The sources of information patients accessed were considered to influence participation in decision-making. Health professionals distinguished between credible and noncredible sources. Credible sources comprised mainstream health 
services and associations based on empirical evidence, such as ALS patient association information kits, and health research-based websites. Conversely, noncredible sources lacked an evidence base, but were easily accessed via the Internet, such as websites selling herbal remedies. While acknowledging the benefits of the Internet as an accessible source of high-quality, research-based information, participants were concerned about the ability of the patient to discern between credible websites and those promoting false hopes of cures and treatments. Clinicians reported a sense of responsibility to monitor the quality of information accessed by patients, and to provide guidance on the range of evidence-based information available (quote 7).

Practitioners were wary of crushing patients' sense of hope. However, they considered poor quality information compounded patients' difficulty accepting the inevitable nature of their condition. Some information sources were seen to create unrealistic expectations of the services health professionals could offer, and the outcomes that could be achieved (quote 8). Participants reflected that many patients' wish for a cure drove them to collect misleading information and develop false hopes that were counterproductive to accepting and adjusting to their condition. Until patients and family members had put aside hopes of a cure, appropriate and effective decisions for symptom management could not be made.

\section{Patient-carer relationship}

Clinicians identified decision-making barriers arising from family dynamics, and in particular the patient-carer relationship. Carers played a vital role in ALS decision-making. Decisions regarding employment, artificial nutrition and hydration, home modifications and accommodation were reported to have considerable influence upon the carers' quality of life. Decision-making was disrupted if the patient and carer could not reach agreement, or when the patient's poor decision-making put the well-being of the carer at risk (quote 9). Respondents also reported instances when carers had a negative influence on decision-making discussions. Some carers were reported to take a gate-keeping role that blocked access of the health professional to the patient, and prevented patients from receiving services and information (quote 10).

\section{Health system factors}

Barriers relating to the health system emerged as a further set of factors that impacted on patient decision-making processes. Health system barriers were the capacity for appropriately timed diagnosis and symptom management, access to ALS-specific resources, and interprofessional communication (Table 4).

\section{Timing of diagnosis and symptom management}

Participants from diagnostic, management, and end-of-life services expressed concern about the time lag between patients reporting symptoms and receiving a diagnosis of ALS. The heterogeneity and subtlety of ALS symptoms created delays in gaining the diagnosis, and decision-making to optimize symptom management. Participants stated that limited awareness of ALS by nonspecialist health care providers hindered timely referrals to ALS services (quote 11). Once symptoms were recognized as ALS, access to specialized services became the next challenge for patients and their primary health care professionals. Again, time became a critical and significant problem in terms of effective negotiation of symptom management (quote 12).

Furthermore, access to health services was identified as a particular concern for patients who lived outside of the clinic catchment area. Health professionals stated that "out of zone" patients were disadvantaged by long waiting lists for assessments, interventions, and equipment, all of which impacted on their ability to make decisions about their safety and quality of life (quote 13). Even when patients were able to access specialized services, physical resource constraints compromised care options. Participants reported frustration with long waiting times for equipment, when extended delays made equipment obsolete for rapidly deteriorating patients (quote 14).

Clinicians identified well-timed information as crucial to the patient's ability to make decisions. Respondents agreed that patients and families should be informed as early as possible about the diagnosis, prognosis, and expected course of disease progression (quote 15). However, knowing when to do so, without overwhelming both patient and carer, was a difficult decision, and specific to each case. The ability to judge optimal timing for provision of information challenged health professionals both as individuals and as a team (quote 16). Participants viewed the timing of information as dependent on the patient's readiness to hear it. Decisionmaking progressed once patients reached some level of acceptance of their condition. Clinicians were then able to coordinate the type and amount of information they presented to the patient (quote 17).

\section{Access to ALS-specific resources}

Health professionals stated that the wider health system created barriers to collaborative and patient-centered decision-making. 
Table 4 Health system factors

Timing of diagnosis and symptom management

II. "I think it all goes back to the clinical acumen of the first few people that they see, and the more they know about the disease. If you're not thinking about it, you're never going to diagnose it. So, the more they know, then the better they're going to get, to pick it up sooner. Sometimes you can hardly blame them, because the symptom has been so subtle, that I can see why the GP was hunting other causes, there are much more common things that could have mimicked that subtle symptom." (HP26)

12. "I think that is an obstacle to timely management of patients ... my waiting list is 18 months. Now, somebody with a possible diagnosis of ALS will bypass that, be seen urgently. But even so, it's not as though I can see them tomorrow. It's still going to be several weeks." (HPI8)

13. "There are massive waiting lists if you were to go and see a gastroenterologist in the public system. So three months time, when you need it now, is a bit too long to wait for these patients." (HP24)

14. "It adds a real stress when people are clearly progressing, but then you're waiting for something to happen. And in the meantime, they're struggling until that happens. And by the time that thing happens, the thing you've requested is out of date. So then you're asking for something else. So you're always playing catch up." (HP27)

I5. "I think that's with feeding and ventilation, as well ... you have to raise it very early. And they have, they're big decisions to make. And, not going ahead with it has very significant consequences. So in the discussion you have to say if you don't do this, these are the dreadful things that are going to happen to you, and if you do do it, these are the dreadful things that are going to happen to you." (HP3)

16. "The information is important, but the time that you give the information will be also important, because you might give too early, and they forget or don't hear what you said. And we have then people coming who say, 'But I wasn't told that.' It was clearly written that we informed people at certain stages, but they just don't remember, because I don't think they were ready to hear." (HP28)

17. "I try to pace myself, not to give them all the information from the beginning of the disease until the end of life, right in the first session. They won't remember it; it's going to be overwhelming, l'm not sure if they would want to come back to the clinic again either." (HP26)

Access to ALS-specific resources

18. "There are massive barriers by the health system ... We know that managing patients in a multidisciplinary clinic is far better than in a general neurology clinic. They live longer, and more importantly their quality of life is better. None of those things are funded. And that presents an enormous problem for us. As a result, you can't provide dedicated services, you can't institute things on time, and it's a huge issue." (HP29)

19. "I would love there to be a set guideline ... but we're not funded for that clinic [for] our positions. So I need to be very careful about how much work I put into it. And that's probably why I haven't. There's a lot of ideas I have about formalizing these things, but we're just not funded." (HP22)

Interprofessional communication

20. "I think often the structure of the clinic makes that difficult because $\mathrm{Dr} X$ saw her first, documented in the notes, which is great, but it really would have been nice to talk to Dr X verbally, before [the patient] came into our rooms. Sometimes it can be quite difficult. Sometimes the neurologist might write 'Not for PEG' in big writing, but they don't say why." (HP22)

2I. "I find a lot of my work is afterwards, following up, referring. And because these patients come from all over, trying to track down which community dietitian services this area, it's like going through the path of calling this hospital, then they say no, you need to call this community dietitian, this community dietitian says, 'No, I don't see patients with tubes' or 'I only see patients who are immobile, and try this person'." (HP24)

22. "But suddenly they came across $\mathrm{Dr} Y$ and $\mathrm{Dr} Y$ came across them and they said 'What are you doing? We do this already.' And so, I guess another barrier is communication, and making sure the entire medical, any health profession is aware of what's available where. And that's not very well done." (HPI8)

Abbreviation: ALS, amyotrophic lateral sclerosis; HP, health professional.

Health service funding was frequently mentioned as blocking the delivery of specialized ALS multidisciplinary clinic services. Service funding impacted on decision-making by: restricting the funding of dedicated specialist ALS health professional positions; limiting clinic resources, such as production of evidence-based clinical guidelines; limiting patient numbers with access to specialist clinics; and curtailing health professional education and awareness of the specific needs of people with ALS (quote 18). Health professionals reported frustration with constraints imposed by these factors largely outside of their control, and considered they had few avenues for improving the service they could offer (quote 19).

\section{Interprofessional communication}

Participants cited communication difficulties between health professionals as a barrier to decision-making in multidisciplinary ALS practice. Breakdowns in interprofessional communication were reported to disrupt information exchange and implementation of collaborative, patient-centered decisions. During busy clinic sessions, tight appointment schedules restricted sharing of verbal and written information between the clinicians (quote 20). Communication with external health providers was also problematic. Participants reported spending lengthy periods of time attempting to contact external practitioners for referral and handover, which delayed communication of patient decisions (quote 21). Health professionals agreed that effective multidisciplinary ALS care relied on well-timed and coordinated discussion between the patient and carer, the clinic team and external providers. For example, insertion of percutaneous endoscopic gastrostomy was frequently cited as a decision vulnerable to communication blocks. 
Additionally, respondents identified information and communication gaps between their clinic and health providers who were unaware of the specialized clinic service (quote 22). These gaps were seen to result in disruptions to coordination of care and duplication of services.

\section{Decision-making facilitators}

Health professionals stated that working in a multidisciplinary model of care enhanced their role in decision-making, when supported by access to ALS research information and clinician education websites. They considered successful decision-making for symptom management to be the result of meeting the patient at their point of need. Three interrelated factors promoted this objective, ie, collaborative teamwork, effective communication systems which underpinned that teamwork, and evidence-based clinical information (Table 5).

Participants valued teamwork as a key component to effective multidisciplinary ALS care. They viewed teamwork as a means of sharing of information, monitoring of the patient's condition and providing a coordinated, timely response to changing patient needs (quotes 23 and 24). Practitioners identified emerging evidence that they wished to incorporate into their clinic service, in particular, the development and use of clinical pathways and guidelines. They nominated three important applications of guidelines for decision-making within the multidisciplinary ALS team: to assist provision of clear information to health professionals, patients, and families; to provide structure and timeframes to facilitate planning with patients; and to give clarification of roles and responsibilities for decision-making within the multidisciplinary team (quote 25). Respondents also supported the introduction of clinical guidelines to reduce specific gaps in their service. These included the use of routine screening for cognitive and behavioral change, and the completion of advance care plans with their patients. In essence, the health professionals sought a service that allowed them to be a step ahead of patient needs to support timely decision-making (quote 26).

\section{Discussion}

This research set out to explore decision-making from the perspective of health professionals in an attempt to identify factors that influence patient-centered decision-making in specialized multidisciplinary ALS care. The findings reveal that health professionals perceive patient and health system factors as shaping patient-centered decision-making in ALS care. Patient factors were: the ability to accept the diagnosis; types of information sourced by patients; and the patientcarer relationship. Health system factors were: the timing of diagnosis and symptom management; access to ALS-specific resources; and interprofessional communication. Interrelated facilitators promoted effective patient-centered decisionmaking, ie, teamwork supported by strong interprofessional communication and evidence-based information.

These findings confirm previous studies that identified aspects of ALS patient management that have the potential to create barriers to patient care. Patient difficulties with acceptance, ${ }^{39}$ insight, ${ }^{52}$ use of avoidance and denial as a coping strategy, ${ }^{53-56}$ and cognitive and behavioral changes ${ }^{7,57}$ are well documented. The challenges of ALS patients' unrealistic expectations, and acceptance of their condition, to decisionmaking are also found across palliative care. ${ }^{35}$ Patient-centered decision-making relies on a fine balance between the timing of information and service provision, and the perceived readiness of patients to receive them. Dilemmas concerning timing of end-of-life discussions with ALS patients are consistent with broader palliative care research. ${ }^{58,59}$ Health professionals' concerns about ALS patients' discernment of credible information sources have been alleviated by evidencebased and open access resources. For example, resources such as ALS association websites, "ALSUntangled"60 and 'PatientsLikeMe' ${ }^{61}$ promote ALS patients' and families' health literacy and information-seeking skills ${ }^{27}$ by use of the Internet

Table 5 Decision-making facilitators

23. "I think what we have to be able to do is be very ready with information, be very responsive to anything ... it's about trying to be responsive to them when they are ready to hear. So I think having good information to hand, being as responsive as you can." (HPI5)

24. "I think good decision-making too also comes from being given really good information ... and multidisciplinary stuff, and everyone singing from the same page." (HPI2)

25. "I think if we had more evidence for everything we do it would make life much easier, because we could say, 'When you get to this point in your disease, you should do this'. Locally, specific to here, a clear pathway of care, and a policy and procedure would really help in terms of just not like collating the evidence and getting agreement on that, but also like literally step by step in our clinic, based on the barriers within the clinic." (HP22)

26. “... l'm suggesting [a] bucket of money, resource, some other philosophy whereby people are dedicated to being reactive to, or even predictive of [patients'] changes, so as things are starting to change or develop, the other [service] changes and developments can be put in place." (HP27)

Abbreviation: HP, health professional. 
and emerging technology. ${ }^{60,62}$ Such resources further equip health professionals to discuss the credibility of advertised treatments.

Similarly, the perceived health system barriers to patient decision-making reflect recognized challenges to ALS patient care. Delays in diagnosis and health service access are known to impede ALS patients' planning for the future, ${ }^{63}$ and impact negatively on patients' experiences with ALS care. ${ }^{64,65}$ Despite the emergence of specialized multidisciplinary ALS care, difficulties persist with regard to access to specialized services and information. ${ }^{66,67}$

The findings of this study highlight a disparity between health professionals' experience of patient decision-making, and clinicians' understanding of the clinical evidence and their subsequent approach to practice. ${ }^{68}$ This point corresponds with studies that demonstrate the influence of patients' individual perceptions and experiences on their participation in care. ${ }^{56,69,70}$ Additionally, divergence has been noted between patient expectations and experience of ALS services, ${ }^{71}$ patient and provider goals for treatment ${ }^{72}$ and the care values and priorities of patients, carers, and health professionals..$^{73}$ These results confirm the findings in cancer care $^{74}$ and primary care. ${ }^{75}$

This study extends and adds to our knowledge base by exploring the impact of ALS in a multidisciplinary ALS care setting. ALS represents a known, common, and inevitable path of decline, leading to death. The background of progressive degeneration and limited treatment options creates a "worst case" scenario for patient-centered decisionmaking. ALS presents a case study of the potential ambiguity of clinical decision-making, ie, the challenge of reconciling evidence-based practice and patient-centered care. The two questions this study raises are: when is it appropriate for health professionals to intervene proactively if they consider that patients are making decisions that will impact negatively on them in the future; and if it is appropriate for them to intervene, how far should they proceed? Proactive team approaches have the potential to prevent crisis situations and costly interventions that may result from delays in decisionmaking. ${ }^{31,34,76,77}$ However, the objective of a proactive, patient-centered, and collaborative multidisciplinary team is compromised by the impact of ALS on the patient and health system limitations. The challenge facing health professionals is how to bridge this gap.

The implication for practice that may begin to answer the above questions is the necessity for actions to bridge the gap between ALS research and current clinical practice. ALS research recommends three practice changes for specialized multidisciplinary care that relate to our findings. These include early detection of cognitive and behavioral changes in patients, ${ }^{78,79}$ assessment of patients' adjustment and coping, ${ }^{39}$ and addition of psychology services to the specialized multidisciplinary ALS team. ${ }^{8,80}$ These recommendations are yet to be systematically implemented in clinical care. The addition of psychology services could contribute to our understanding of the full impact of ALS on patients, to inform health professionals better about the challenges to and limitations of patient engagement and decision-making. This knowledge can support clinicians' judgment, as individuals and within a team, to tailor care to the needs of each patient.

The development of clinical guidelines that accommodate patient strengths, limitations, and barriers could enhance the efficacy of decision-making. Current guidelines for patient management do not account for the challenges to patient decision-making. We see that there is scope for inclusion of evidence on the impact of ALS on quality and timing of decision-making. This information can be aligned with a focus on discussion of patients' physical, psychosocial, and cognitive-behavioral needs. Even so, clinicians may be restricted in their capacity to assist the patient's ability to accept their circumstances, due to the complex and individual nature of acceptance. ${ }^{56}$ While shared decisionmaking is thought to reduce conflict between patient and carer, ${ }^{81}$ this is untested in ALS care settings. Amelioration of barriers presented by the complexities of the patient-carer relationship ${ }^{82}$ is beyond the scope of multidisciplinary ALS care, and external counseling services may be needed to address relationship issues.

A limitation of this study is that it comprised a sample of health professionals from two clinics in one country, operating on similar model. However, confirmation of findings by the wider ALS and palliative care literature suggest that the concerns raised by health professionals are not unique to the participating sites and clinicians. Additionally, this study highlights aspects of specialized multidisciplinary ALS care that are yet to be examined. The experiences of patients and carers in decision-making are distinct from those of health professionals, ${ }^{83}$ and require exploration to identify their distinct perspectives. More broadly, there has been no examination of the impact of specialized multidisciplinary ALS care on patient satisfaction, ${ }^{36}$ or health professional satisfaction and well-being. The emotional and professional difficulties faced by ALS and palliative care clinicians ${ }^{41}$ may be better supported within a dedicated model of ALS care. This requires investigation. 
There are further issues raised by this study that suggest avenues for research. Health professionals speculated that patients who accept their condition earlier may engage in timelier decision-making. This is untested at this time in ALS research. Large-scale studies that build on recent investigations of patient adaptation to an ALS diagnosis ${ }^{39}$ and the barriers that cognitive and behavioral change present ${ }^{7}$ may be used to determine better the impact of ALS on patient decisionmaking, and the means of improving patient engagement.

\section{Conclusion}

This study lays a foundation for expanding our understanding of patient decision-making from health professional perspectives. Aligned with further research to examine the experience and perspectives of patients and carers, such studies will aid in the construction of an evidence-based body of knowledge to improve multidisciplinary ALS practice and ultimately patient care.

\section{Acknowledgments}

This research project was funded by the Australian Government Department of Health and Ageing. The authors wish to thank all those who took part in this study.

\section{Disclosure}

The authors report no conflicts of interest in this work.

\section{References}

1. Strong MJ. The syndromes of frontotemporal dysfunction in amyotrophic lateral sclerosis. Amyotroph Lat Scler. 2008;9(6):323-338.

2. Strong MJ, Grace GM, Freedman M, et al. Consensus criteria for the diagnosis of frontotemporal cognitive and behavioural syndromes in amyotrophic lateral sclerosis. Amyotroph Lateral Scler. 2009; 10(3):131-146.

3. Miller RG, Jackson CE, Kasarskis EJ, et al. Practice parameter update: the care of the patient with amyotrophic lateral sclerosis: multidisciplinary care, symptom management, and cognitive/behavioral impairment (an evidence-based review): report of the Quality Standards Subcommittee of the American Academy of Neurology. Neurology. 2009;73(15):1227-1233.

4. Mitsumoto H, Bromberg M, Johnston W, et al. Promoting excellence in end-of-life care in ALS. Amyotroph Lateral Scler Other Motor Neuron Disord. 2005;6(3):145-154.

5. Neudert C, Oliver D, Wasner M, Borasio GD. The course of the terminal phase in patients with amyotrophic lateral sclerosis. J Neurol. 2001;248(7):612-616.

6. Traynor BJ, Codd MB, Corr B, Forde C, Frost E, Hardiman OM. Clinical features of amyotrophic lateral sclerosis according to the El Escorial and Airlie House diagnostic criteria: A population-based study. Arch Neurol. 2000;57(8):1171-1176.

7. Lillo P, Mioshi E, Zoing MC, Kiernan MC, Hodges JR. How common are behavioural changes in amyotrophic lateral sclerosis? Amyotroph Lateral Scler. 2011;12(1):45-51.

8. Hardiman O. Multidisciplinary care in motor neurone disease. In: Kiernan MC, editor. The Motor Neurone Disease Handbook. Sydney, Australia: MJA Books; 2007.
9. Traynor BJ, Alexander M, Corr B, Frost E, Hardiman O. Effect of a multidisciplinary amyotrophic lateral sclerosis (ALS) clinic on ALS survival: a population based study, 1996-2000. J Neurol Neurosurg Psychiatry. 2003;74(9):1258-1261.

10. Van den Berg JP, Kalmijn S, Lindeman E, et al. Multidisciplinary ALS care improves quality of life in patients with ALS. Neurology. 2005;65(8):1264-1267.

11. Oliver DJ, Turner MR. Some difficult decisions in ALS/MND. Amyotroph Lateral Scler. 2010;11(4):339-343.

12. Vesey S, Leslie P, Exley C. A pilot study exploring the factors that influence the decision to have PEG feeding in patients with progressive conditions. Dysphagia. 2008;23(3):310-316.

13. Albert SM, Whitaker A, Rabkin JG, et al. Medical and supportive care among people with ALS in the months before death or tracheostomy. J Pain Symptom Manage. 2009;38(4):546-553.

14. Lemoignan J, Ells C. Amyotrophic lateral sclerosis and assisted ventilation: how patients decide. Palliat Support Care. 2010;8(2):207-213.

15. Ward AL, Sanjak M, Duffy K, et al. Power wheelchair prescription, utilization, satisfaction, and cost for patients with amyotrophic lateral sclerosis: preliminary data for evidence-based guidelines. Arch Phys Med Rehabil. 2010;91(2):268-272.

16. Murphy J. "I Prefer Contact This Close": perceptions of AAC by people with motor neurone disease and their communication partners. Augment Altern Commun. 2004;20(4):259-271.

17. Burchardi N, Rauprich O, Hecht M, Beck M, Vollmann J. Discussing living wills. A qualitative study of a German sample of neurologists and ALS patients. $J$ Neurol Sci. 2005;237(1-2):67-74.

18. Albert SM, Murphy PL, Del Bene ML, Rowland LP. Prospective study of palliative care in ALS: choice, timing, outcomes. J Neurol Sci. 1999;169(1-2):108-113.

19. Munroe CA, Sirdofsky MD, Kuru T, Anderson ED. End-of-life decision making in 42 patients with amyotrophic lateral sclerosis. Respir Care. 2007;52(8):996-999.

20. Astrow AB, Sood JR, Nolan MT, et al. Decision-making in patients with advanced cancer compared with amyotrophic lateral sclerosis. J Med Ethics. 2008;34(9):664-668.

21. Coulter A, Ellins J. Effectiveness of strategies for informing, educating, and involving patients. BMJ. 2007;335(7609):24-27.

22. Legare F, Ratte S, Stacey D, et al. Interventions for improving the adoption of shared decision making by healthcare professionals. Cochrane Database Syst Rev. 2010;5:CD006732.

23. Nolan MT, Hughes M, Narendra DP, et al. When patients lack capacity: the roles that patients with terminal diagnoses would choose for their physicians and loved ones in making medical decisions. J Pain Symptom Manage. 2005;30(4):342-353.

24. Nolan MT, Hughes MT, Kub J, et al. Development and validation of the Family Decision-Making Self-Efficacy Scale. Palliat Support Care. 2009;7(3):315.

25. Mockford C, Jenkinson C, Fitzpatrick R. A Review: carers, MND and service provision. Amyotroph Lateral Scler. 2006;7(3):132-141.

26. Hardiman O, Traynor BJ, Corr B, Frost E. Models of care for motor neuron disease: setting standards. Amyotroph Lateral Scler Other Motor Neuron Disord. 2002;3(4):182-185.

27. Chiò A, Montuschi A, Cammarosano S, et al. ALS patients and caregivers communication preferences and information seeking behaviour. Eur J Neurol. 2008;15(1):55-60.

28. Chiò A, Borasio GD. Breaking the news in amyotrophic lateral sclerosis. Amyotroph Lateral Scler Other Motor Neuron Disord. 2004;5(4): 195-201.

29. Albert SM, Murphy PL, Del Bene ML, Rowland LP. A prospective study of preferences and actual treatment choices in ALS. Neurology. 1999;53(2):278-283.

30. Hirano Y, Yamazaki Y. Ethical issues in invasive mechanical ventilation for amyotrophic lateral sclerosis. Nurs Ethics. 2010;17(1):51-63.

31. Seeber AA, Hijdra A, Vermeulen M, Willems DL. Discussions about treatment restrictions in chronic neurologic diseases: a structured review. Neurology. 2012;78(8):590-597. 
32. Sulmasy DP, Hughes MT, Thompson RE, et al. How would terminally ill patients have others make decisions for them in the event of decisional incapacity? A longitudinal study. J Am Geriatr Soc. 2007;55(12): 1981-1988.

33. Albert S, Rabkin J, Bene MD, et al. Wish to die in end-stage ALS. Neurology. 2005;65(1):68-74.

34. Oliver D. Ventilation in motor neuron disease: difficult decisions in difficult circumstances. Amyotroph Lateral Scler Other Motor Neuron Disord. 2004;5(1):6-8.

35. Bélanger E, Rodríguez C, Groleau D. Shared decision-making in palliative care:a systematic mixed studies review using narrative synthesis. Palliat Med. 2010;25(3):242-261.

36. Foley G, Timonen V, Hardiman O. Experience of services as a key outcome in amyotrophic lateral sclerosis (ALS) care: the case for a better understanding of patient experiences. Am J Hosp Palliat Care. 2012;29(5):362-367.

37. Dybwik K, Nielsen EW, Brinchmann BS. Home mechanical ventilation and specialised health care in the community: between a rock and a hard place. BMC Health Serv Res. 2011;11:115.

38. Carter H, McKenna C, MacLeod R, Green R. Health professionals' responses to multiple sclerosis and motor neurone disease. Palliat Med. 1998;12(5):383-394.

39. Hugel H, Pih N, Dougan CP, Rigby S, Young CA. Identifying poor adaptation to a new diagnosis of motor neuron disease: a pilot study into the value of an early patient-led interview. Amyotroph Lateral Scler. 2010;11(1-2):104-109.

40. Bromberg MB, Schenkenberg T, Brownell AA. A survey of stress among amyotrophic lateral sclerosis care providers. Amyotroph Lateral Scler. 2011;12(3):162-167.

41. Melo CG, Oliver D. Can addressing death anxiety reduce health care workers' burnout and improve patient care? J Palliat Care. 2011;27(4):287-295.

42. Kiernan MC, Vucic S, Cheah BC, et al. Amyotrophic lateral sclerosis. Lancet. 2011;377(9769):942-955.

43. Liamputtong P. Qualitative Research Methods. 3rd ed. Melbourne, Australia: Oxford University Press; 2009.

44. Emanuel EJ, Emanuel LL. Four models of the physician-patient relationship. JAMA. 1992;267(16):2221-2226.

45. Degner LF, Sloan JA. Decision making during serious illness: what role do patients really want to play? J Clin Epidemiol. 1992;45(9): 941-950.

46. Charles C, Gafni A, Whelan T. Decision-making in the physician-patient encounter: revisiting the shared treatment decision-making model. Soc Sci Med. 1999;49(5):651-661.

47. Degner LF, Sloan JA, Venkatesh P. The Control Preferences Scale. Can J Nurs Res. 1997;29(3):21-43.

48. O’Connor AM. Ottowa decision support framework to address decisional conflict, 2006. Available from: http:/www.ohri.ca/decisionaid. Accessed July 16, 2012.

49. Nolan MT, Kub J, Hughes MT, et al. Family health care decision making and self-efficacy with patients with ALS at the end of life. Palliat Support Care. 2008;6(3):273-280.

50. Creswell JW. Research Design: Qualitative, Quantitative and Mixed Methods Approaches. 3rd ed. Thousand Oaks, CA: Sage Publications; 2009.

51. Braun V, Clarke C. Using thematic analysis in psychology. Qual Res Psychol. 2006;3:77-101.

52. Woolley SC, Moore DH, Katz JS. Insight in ALS: awareness of behavioral change in patients with and without FTD. Amyotroph Lateral Scler. 2010;11(1-2):52-56.

53. Hogg KE, Goldstein LH, Leigh PN. The psychological impact of motor neurone disease. Psychol Med. 1994;24(3):625-632.

54. Brown WA, Mueller PS. Psychological function in individuals with amyotrophic lateral sclerosis (ALS). Psychosom Med. 1970;32(2):141-152.

55. Houpt JL, Gould BS, Norris FH Jr. Psychological characteristics of patients with amyotrophic lateral sclerosis (ALS). Psychosom Med. 1977;39(5):299-303.
56. Locock L, Ziebland S, Dumelow C. Biographical disruption, abruption and repair in the context of motor neurone disease. Sociol Health Illn. 2009;31(7):1043-1058.

57. Witgert M, Salamone AR, Strutt AM, et al. Frontal-lobe mediated behavioral dysfunction in amyotrophic lateral sclerosis. Eur J Neurol. 2010;17(1):103-110.

58. Spathis A, Booth S. End of life care in chronic obstructive pulmonary disease: in search of a good death. Int J Chron Obstruct Pulmon Dis. 2008;3(1):11-29.

59. Clayton JM, Butow PN, Tattersall MH. When and how to initiate discussion about prognosis and end-of-life issues with terminally ill patients. J Pain Symptom Manage. 2005;30(2):132-144.

60. Bedlack R, Hardiman O. ALSUntangled (ALSU): a scientific approach to off-label treatment options for people with ALS using tweets and twitters. Amyotroph Lateral Scler. 2009;10(3):129-130.

61. Frost JH, Massagli MP, Wicks P, Heywood J. How the social web supports patient experimentation with a new therapy: The demand for patient-controlled and patient-centered informatics. AMIA Anпu Sутр Proc. 2008:217-221.

62. Frost J, Massagli M. PatientsLikeMe: the case for a data-centered patient community and how ALS patients use the community to inform treatment decisions and manage pulmonary health. Chron Respir Dis. 2009;6(4):225-229.

63. Chiò A. ISIS survey: an international study on the diagnostic process and its implications in amyotrophic lateral sclerosis. J Neurol. 1999; 246 Suppl 3:III1-III5.

64. O'Brien MR, Whitehead B, Jack BA, Mitchell JD. From symptom onset to a diagnosis of amyotrophic lateral sclerosis/motor neuron disease (ALS/MND): experiences of people with ALS/MND and family carers - a qualitative study. Amyotroph Lateral Scler. 2011;12(2): 97-104.

65. Hugel H, Grundy N, Rigby S, Young CA. How does current care practice influence the experience of a new diagnosis of motor neuron disease? A qualitative study of current guidelines-based practice. Amyotroph Lateral Scler. 2006;7(3):161-166.

66. Foley G, Timonen V, Hardiman O. Patients' perceptions of services and preferences for care in amyotrophic lateral sclerosis: a review. Amyotroph Lateral Scler. 2012;13(1):11-24.

67. Foley G, O'Mahony P, Hardiman O. Perceptions of quality of life in people with ALS: effects of coping and health care. Amyotroph Lateral Scler. 2007;8(3):164-169.

68. Foley G. The complexity of care in amyotrophic lateral sclerosis. Amyotroph Lateral Scler. 2011;12(3):160-161.

69. Roach AR, Averill AJ, Segerstrom SC, Kasarskis EJ. The dynamics of quality of life in ALS patients and caregivers. Ann Behav Med. 2009; 37(2):197-206

70. Fegg MJ, Wasner M, Neudert C, Borasio GD. Personal values and individual quality of life in palliative care patients. J Pain Symptom Manage. 2005;30(2):154-159.

71. Hughes RA, Sinha A, Higginson IJ, Down K, Leigh PN. Living with motor neurone disease: lives, experiences of services and suggestions for change. Health Soc Care Community. 2005;13(1):64-74.

72. Rodriguez KL, Young AJ. Patients' and healthcare providers' understandings of life-sustaining treatment: are perceptions of goals shared or divergent? Soc Sci Med. 2006;62(1):125-133.

73. Brown JB. User, carer and professional experiences of care in motor neurone disease. Prim Health Care Res Dev. 2003;4:207-217.

74. Butow PN. Shared decision making in cancer care. Clin Psychol. 2005;9(2):54-58.

75. Ford S, Schofield T, Hope T. Are patients' decision-making preferences being met? Health Expect. 2003;6(1):72-80.

76. Tsou AY, Karlawish J, McCluskey L, Xie SX, Long JA. Predictors of emergent feeding tubes and tracheostomies in amyotrophic lateral sclerosis (ALS). Amyotroph Lateral Scler. 2012;13(3):318-325.

77. McKim DA, King J, Walker K, et al. Formal ventilation patient education for ALS predicts real-life choices. Amyotroph Lateral Scler. 2012;13(1):59-65. 
78. Woolley SC. Utility of the amyotrophic lateral sclerosis cognitive behavioural screen (ALS CBS ${ }^{\mathrm{TM}}$ ). Neurodegen Dis Manage. 2011;1(6) 473-479.

79. Flaherty-Craig C, Brothers A, Yang C, Svoboda R, Simmons Z. Declines in problem solving and anosognosia in amyotrophic lateral sclerosis: Application of guilford's structure of intellect theory. Cogn Behav Neurol. 2011;24(1):26-34.

80. Barson FP, Kinsella GJ, Ong B, Mathers SE. A neuropsychological investigation of dementia in motor neurone disease (MND). J Neurol Sci. 2000;180(1-2):107-113.
81. Bolmsjö I, Hermerén G. Conflicts of interest: Experiences of close relatives of patients suffering from amyotrophic lateral sclerosis. Nurs Ethics. 2003;10(2):186-198.

82. Atkins L, Brown RG, Leigh PN, Goldstein LH. Marital relationships in amyotrophic lateral sclerosis. Amyotroph Lateral Scler. 2010;11(4): 344-350.

83. Steinhauser KE, Clipp EC, McNeilly M, Christakis NA, McIntyre LM, Tulsky JA. In search of a good death: observations of patients, families, and providers. Ann Intern Med. 2000;132(10):825-832.

\section{Publish your work in this journal}

Patient Preference and Adherence is an international, peer-reviewed, open access journal focusing on the growing importance of patient preference and adherence throughout the therapeutic continuum. Patient satisfaction, acceptability, quality of life, compliance, persistence and their role in developing new therapeutic modalities and compounds to optimize clinical outcomes for existing disease states are major areas of interest. This journal has been accepted for indexing on PubMed Central. The manuscript management system is completely online and includes a very quick and fair peer-review system. Visit http://www.dovepress.com/ testimonials.php to read real quotes from published authors.

Submit your manuscript here: http://www.dovepress.com/patient-preference-and-adherence-journal 